\title{
To use or not to use: an update on licit and illicit ketamine use
}

This article was published in the following Dove Press journal:

Substance Abuse and Rehabilitation

15 March 20II

Number of times this article has been viewed

Jih-Heng $\mathrm{Li}^{\prime}$

Balasingam Vicknasingam ${ }^{2}$

Yuet-wah Cheung ${ }^{3}$

Wang Zhou ${ }^{4}$

Adhi Wibowo Nurhidayat ${ }^{5}$

Don C Des Jarlais ${ }^{6}$

Richard Schottenfeld ${ }^{7}$

'College of Pharmacy, Kaohsiung Medical University, Kaohsiung,

Taiwan; ${ }^{2}$ National Centre for Drug Research, Universiti Sains Malaysia,

Malaysia; ${ }^{3}$ Department of Sociology,

The Chinese University of Hong

Kong, Hong Kong, China; ${ }^{4}$ Wuhan

Center for Disease Control and

Prevention, Wuhan, China; ${ }^{5}$ Drug

Dependence Hospital RSKO, Jakarta,

Indonesia; ${ }^{6}$ Beth Israel Medical

Center, New York, NY; ${ }^{7}$ School of

Psychiatry, Yale University, CT, USA
Correspondence: Jih-Heng Li

College of Pharmacy, Kaohsiung Medical

University, Kaohsiung 80708, Taiwan

Tel +88 673 I2। I0। ext 265 |

Fax +88673210683

Email jhlitox@kmu.edu.tw
Abstract: Ketamine, a derivative of phencyclidine that was developed in the 1960 s, is an anesthetic and analgesic with hallucinogenic effects. In this paper, the pharmacological and toxicological effects of ketamine are briefly reviewed. Ketamine possesses a wide safety margin but such a therapeutic benefit is somewhat offset by its emergence phenomenon (mind-body dissociation and delirium) and hallucinogenic effects. The increasing abuse of ketamine, initially predominantly in recreational scenes to experience a "k-hole" and other hallucinatory effects but more recently also as a drug abused during the workday or at home, has further pushed governments to confine its usage in many countries. Recently, urinary tract dysfunction has been associated with long-term ketamine use. In some long-term ketamine users, such damage can be irreversible and could result in renal failure and dialysis. Although ketamine has not yet been scheduled in the United Nations Conventions, previous studies using different assessment parameters to score the overall harms of drugs indicated that ketamine may cause more harm than some of the United Nations scheduled drugs. Some countries in Southeast and East Asia have reported an escalating situation of ketamine abuse. Dependence, lower urinary tract dysfunction, and sexual impulse or violence were the most notable among the ketamine-associated symptoms in these countries. These results implied that the danger of ketamine may have been underestimated previously. Therefore, the severity levels of the ketamine-associated problems should be scrutinized more carefully and objectively. To prevent ketamine from being improperly used and evolving into an epidemic, a thorough survey on the prevalence and characteristics of illicit ketamine use is imperative so that suitable policy and measures can be taken. On the other hand, recent findings that ketamine could be useful for treating major depressive disorder has given this old drug a new impetus. If ketamine is indeed a remedy for treating depression, more research on the risks and benefits of its clinical use will be indispensable.

Keywords: ketamine, psychedelic effects, urinary tract dysfunction, anti-depressant, cognitive impairment, epidemiology

\section{Introduction}

In many parts of the world including Southeast and East Asia, ketamine abuse is emerging as a major problem while the peak of methamphetamine epidemic may have passed. ${ }^{1,2}$ The use of ketamine along with other "club drugs", such as MDMA (ecstasy), gamma-hydroxybutyric acid (GHB), and flunitrazepam, can develop into various adverse health aftermaths including dependence and specific organ toxicity. Among the club drugs, MDMA use still dominates in the clubs and rave parties. However, it has been reported that ketamine is being used for nonmedical purposes outside of clubs and rave parties in many parts of the world..$^{3-5}$ In fact, ketamine has surpassed other club drugs and even replaced heroin as the predominant drug of abuse in Hong Kong since 
the early 2000s. ${ }^{6}$ In addition, an increasing trend of illicit ketamine use has also been reported in China, Malaysia, and Taiwan. ${ }^{4,7,8}$ Illicit ketamine use may occur alone or in combination with other drugs. In Taiwan, for example, "Trinity" is a description for a sequence of polydrug use at a club with MDMA first, followed by ketamine, and then marijuana. ${ }^{9}$ At the recreational scenes, ketamine is usually called " $\mathrm{K}$ ", "vitamin K", "super K", or "special K".

Ketamine (2-[2-chlorophenyl]-2-[methylamino]cyclohexanone) is a pharmaceutical derived from phencyclidine (PCP) and cyclohexamine. It was originally developed by Parke-Davis Laboratories in 1962 and introduced into clinical usage as an anesthetic in $1970 .{ }^{10-13}$ Often known by its brand names such as Ketofen ${ }^{\circledR}$, Ketalar ${ }^{\circledR}$,

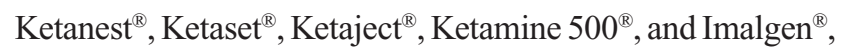
the hydrochloride form of ketamine is rapid-acting and lipid soluble with a short elimination half-life. ${ }^{14-16}$ With adequate doses, a trancelike and cataleptic state with amnesia occurs, producing the so-called dissociative effect. ${ }^{10,11,14}$ Soon after ketamine was developed, its illegal manufacture, distribution, and nonmedical use were reported. ${ }^{17}$ In the 1970 s, the abuse potential of ketamine was noted by both academic and government agencies. ${ }^{18,19}$

Although ketamine abuse has been observed in many parts of the world and there clearly are multiple dangers associated with nonmedical use, it has not been scheduled as a controlled substance by the United Nations. Therefore, the scale of ketamine abuse may not be appropriately assessed. Recently, however, ketamine has been found to have potential for treatment of depression. Since depression is one of the most important diseases that remain to be solved in this century, the promising potential of ketamine as a key for treatment should not be overlooked. Hence, this review aims to briefly describe ketamine's pharmacological and toxicological effects that are associated with its treatment potential and abuse liability so that both academia and incumbent agencies will be addressed in the multiple issues related to ketamine use.

\section{Pharmacology and mechanism of action \\ Anesthesia and analgesia}

Ketamine is a noncompetitive inhibitor of the $N$-methyl-Daspartate (NMDA) glutaminergic receptors, although it can also interact with other receptors, such as opioid receptors and type A gamma-amino-butyric acid receptors at relatively high plasma concentrations. ${ }^{20,21}$ The NMDA receptor (Figure 1), a cation-gated channel receptor permeable primarily to calcium, is involved in sensory input at the spinal, thalamic, limbic, and cortical levels. ${ }^{11}$ The binding of excitatory amino acids (EAA), including glutamate, glycine, and aspartate, to the NMDA receptor causes opening of the channels and eventually leads to neuronal depolarization. An acute dose of ketamine can prevent the influx of calcium ions and blocks the sensory input and impairs limbic functions. ${ }^{11}$ Impairment of memory by ketamine has been shown in laboratory studies. ${ }^{22,23}$ The antagonism of NMDA receptor by ketamine has been associated with the analgesic, dissociative, and neuroprotective effects, while the modulation by ketamine of opioid receptors also contributes to its analgesic effects and is considered to be responsible for its dysphoric effects. ${ }^{14,24}$ In human embryonic kidney cells, ketamine has also been found to inhibit the uptake of norepinephrine and serotonin in a dose-dependent manner, a mechanism that has been postulated to explain its psychomimetic and sympathomimetic effects. ${ }^{25}$ Putting these effects together, the administration of ketamine results in anesthesia, analgesia, tachycardia, increased blood pressure, impaired memory and cognitive function, and visual

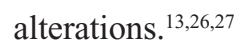

Ketamine is water soluble with a $\mathrm{pKa}$ of 7.5 and a short half-life of 1-3 hours. ${ }^{28}$ It possesses a wide margin of physiological safety but can cause psychological dissociation and results in hallucinations at much smaller doses than therapeutic need. ${ }^{19,29}$ However, unlike most other anesthetics that are cardiorespiratory depressants, ketamine is a stimulant. Such a clinical advantage of causing less respiratory inhibition helps explain why ketamine is still used as a human anesthetic. ${ }^{29}$ For anesthetic purposes, it can be administered intramuscularly to perform minor procedures or administered continuously via an intravenous route. ${ }^{16}$ It can also be administered orally, epidurally, and intrathecally for treatment of postoperative or chronic cancer pain and neuropathic pain control. ${ }^{30,31}$

\section{Stereochemistry and metabolism}

With a chiral center at the $\mathrm{C}-2$ carbon of its cyclohexanone ring, ketamine exists in two optical enantiomers, S-(+)ketamine and R-(-)-ketamine, which differ in their analgesic and anesthetic effects. ${ }^{32}$ Ketamine is pharmaceutically manufactured as a 1:1 racemic mixture of enantiomers. ${ }^{33}$ In cultured rat hippocampal neurons, the $\mathrm{S}-(+)$-enantiomer was shown to be twice as potent as the R-(-)-ketamine on NMDA receptor-activated cation currents. ${ }^{32}$ In human brain, S-(+)-enantiomer binds to the PCP binding site of the NMDA receptor complex with a 4- to 5-fold higher affinity than the R-(-)-ketamine. ${ }^{34}$ 


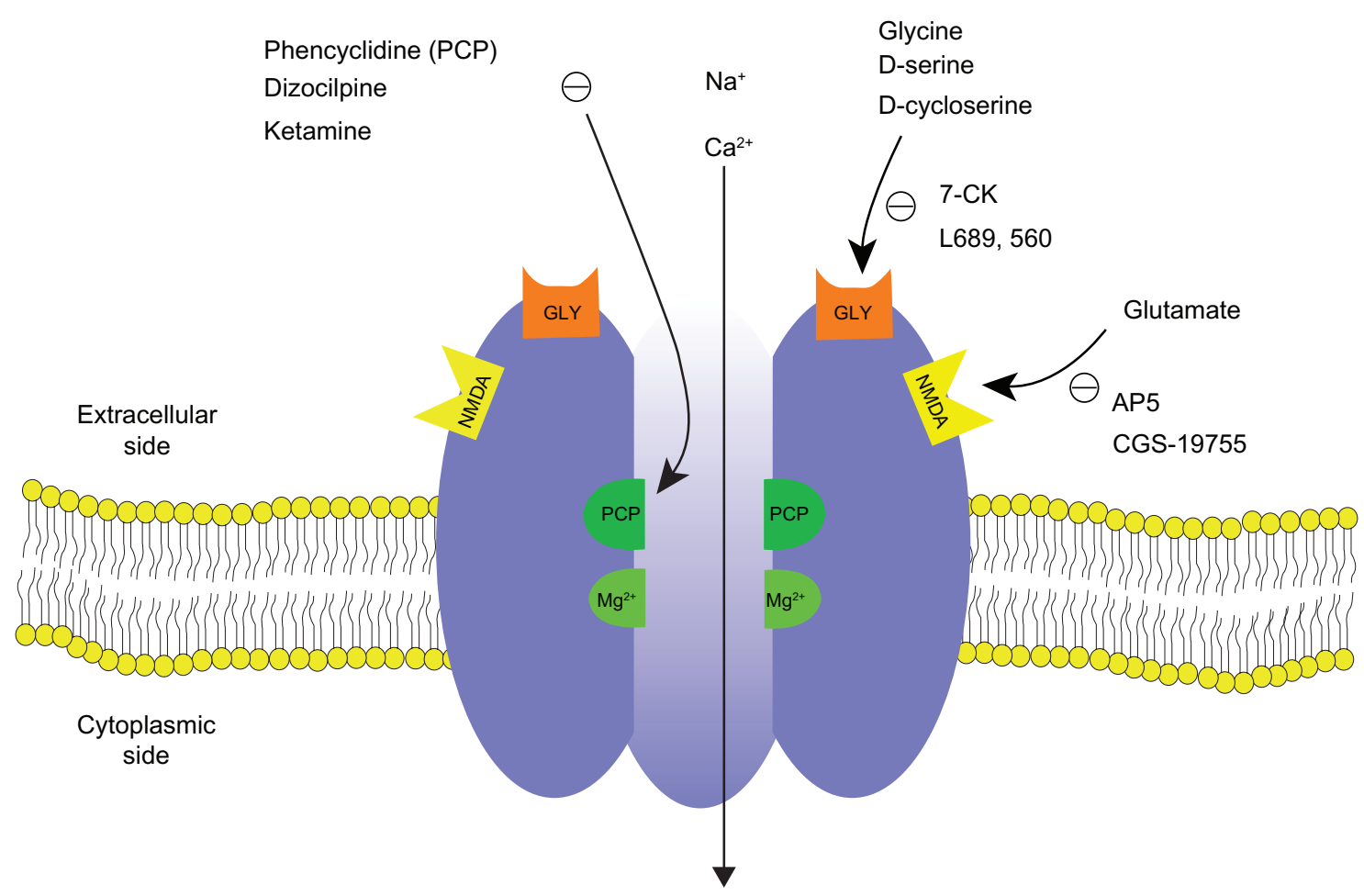

Figure I Schematic diagram of NMDA receptor complex. The NMDA receptor is an ionotropic glutamate receptor for controlling synaptic plasticity and memory function. ${ }^{47,49}$ Glutamate (and NMDA) binds to the agonist site on the NMDA receptors. PCP, ketamine, and dizocilpine bind to the PCP receptor in the inside of the NMDA receptors. Glycine and D-serine bind to a glycine modulatory site on the NMDA receptors. The NMDA receptor is blocked by $\mathrm{Mg}^{2+}$ in a voltage sensitive manner. Activation of NMDA receptor by binding of both glutamate and glycine results in the opening of the channel. This allows voltage-dependent flow of $\mathrm{Na}^{+}$and small amounts of $\mathrm{Ca}^{2+}$ ions into the cell and $\mathrm{K}^{+}$out of the cell. The symbol $(-)$denotes inhibitory effect.

Abbreviations: NMDA, N-methyl-D-aspartate; 7-CK, 7-chlorokynurenic acid; L689,560, trans-2-carboxy-5,7-dichloro-4-phenylaminocarbonyl; AP5, 2-amino-5-phosphonovaleric acid; CGS-19775, cis-4-phosphonomethyl-2-piperidinecarboxylic acid.

By contrast, the R-(-)-enantiomer is more potent than the $\mathrm{S}(+)$-enantiomer for the effect of bronchodilation. This difference appears to be caused by differential actions on receptor-operated calcium channels. ${ }^{35}$

In animals, ketamine is metabolized, besides its untransformed form, into norketamine (NK), hydroxynorketamine, and dehydronorketamine (DHNK). ${ }^{36}$ In humans, ketamine is similarly metabolized into metabolites, which can be detected in urine, with DHNK being the most abundant, followed by $\mathrm{NK} \cdot{ }^{37} \mathrm{NK}$ is pharmacologically active with an anesthetic potency approximately one-third of ketamine. The major hepatic enzymes responsible for ketamine $\mathrm{N}$-demethylation are CYP3A4, followed by CYP2B6 and CYP2C9, although large interindividual variability in the metabolism of ketamine exists. ${ }^{37-39}$ The pathway of ketamine metabolism is depicted in Figure 2. It has been reported that concurrent administration of diazepam, which can inhibit hepatic metabolism, can prolong the plasma half-life of ketamine and its metabolites. ${ }^{40}$ In addition, the emergence phenomenon, which is the most frequently reported adverse effect of ketamine, is decreased by the administration of diazepam and other benzodiazepines. ${ }^{41}$

\section{Some implications of ketamine use in psychiatry}

In addition to its original use as an anesthetic and analgesic, ketamine has also been utilized for psychiatric purposes. Some of its applications are briefly discussed as follows:

\section{Recent progress: antidepressant effects}

Recent studies indicated that ketamine possesses rapid antidepressant effects in treatment-resistant patients with major depressive disorder. ${ }^{42}$ Lately it has been reported that 40 minutes after a single subanesthetic intravenous infusion of ketamine hydrochloride $(0.5 \mathrm{mg} / \mathrm{kg})$, the depressive symptoms of the subjects with treatment-resistant bipolar depression were significantly improved. Such an improvement remained significant through day three. ${ }^{43}$ The antidepressant effects of ketamine have been associated with its antagonistic effects on the NMDA receptor or inhibitory effects on the norepinephrine and serotonin transporter function. ${ }^{42,44}$ In contrast, a recent investigation revealed that ketamine treatment can activate the mammalian target of rapamycin (mTOR) pathway to strengthen synapses in the prefrontal cortex of rats. ${ }^{45}$ In rat depression models, blockade of mTOR 
<smiles>CN[C@@]1(c2ccccc2Cl)CCCCC1=O</smiles>

Ketamine<smiles>N[C@@]1(c2ccccc2Cl)CCC=CC1=O</smiles>

5, 6-dehydronorketamine

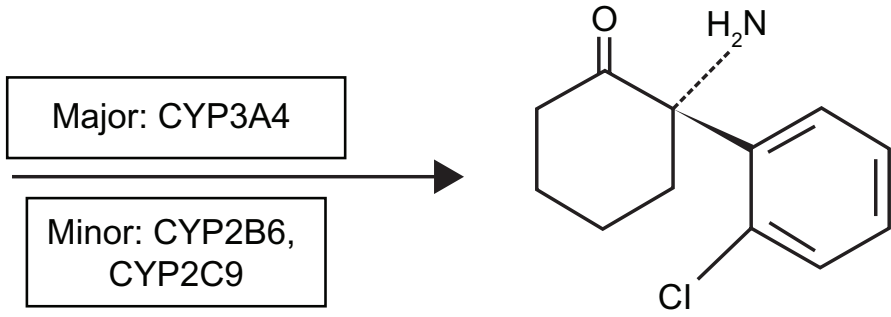

Norketamine

CYP2B6 CYP2A6

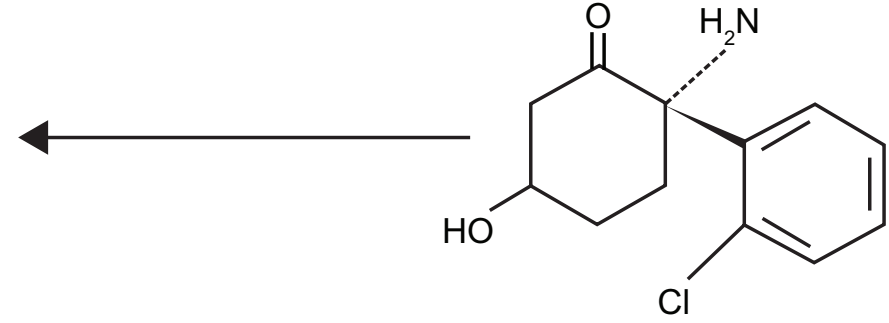

5-hydroxynorketamine

Figure 2 The pathway of ketamine metabolism in phase I. Ketamine is N-demethylated by liver cytochrome P450 enzymes (major: CYP3A4; minor: CYP2B6 and CYP2C9) into norketamine. ${ }^{11,92}$ CYP2B6 and CYP2A6 have been identified to hydroxylate norketamine into 5-hydroxynorketamine. ${ }^{91}$ The chemical structures are depicted for S-ketamine and its metabolites.

signaling also blocked ketamine induction of synaptogenesis and behavioral responses. ${ }^{45}$

Besides ketamine, some psychedelic drugs, such as lysergic acid diethylamide (LSD) and psilocybin, have shown efficacy in treating obsessive-compulsive disorders and addiction as well as depression and anxiety. ${ }^{46}$

Although ketamine-induced antidepressant effect was rapid, its adverse events including dissociation and strange, weird, or bizarre feeling did occur. ${ }^{43}$ In fact, the same intravenous dose of ketamine $(0.5 \mathrm{mg} / \mathrm{kg})$, which was effective for patients with treatment-resistant bipolar depression, has been reported to produce behaviors similar to the positive and negative symptoms of schizophrenia and to evoke symptoms similar to dissociative states. ${ }^{22}$ Furthermore, although glutamate/NMDA receptors may play a pivotal role in the pathophysiology of major depressive disorder, the involvement and interaction of other potential therapeutic targets such as other glutamate receptor families ( $\alpha$-amino3-hydroxy-5-methyl-4-isoxazolepropionic acid receptors, metabotropic glutamate receptors), glutamate transporter EAAC1/2 enhancer, sigma-1 receptors, anti-inflammatory drugs, and antioxidants should not be overlooked. ${ }^{47}$ As major depressive disorder affects more than 120 million people worldwide, the mechanism(s) that underlie the treatment of depression with ketamine and other psychedelics deserve further investigation..$^{48}$

\section{PCP-ketamine/NMDA models of schizophrenia}

Schizophrenia, a severe, persistent, and debilitating psychiatric disorder, is characterized by symptoms that can be divided into three main domains: positive, negative, and cognitive. ${ }^{49}$ The conventional dopamine model or hypothesis attributes symptoms of schizophrenia to a disturbed and hyperactive dopaminergic signal transduction. ${ }^{50,51}$ For example, amphetamine, cocaine, and similar drugs increase levels of dopamine in the brain and can cause "amphetamine psychosis" or "cocaine psychosis", but they may also produce experiences virtually indistinguishable from the positive symptoms of schizophrenia. ${ }^{52}$ In contrast to the dopamine model, several dissociative anesthetics, including PCP and ketamine, exert their unique behavioral effects by blocking the NMDA receptors and induce a psychotomimetic state that closely resembles both positive and negative symptoms of schizophrenia. ${ }^{49,53}$ Over the past several decades many animal models and challenge studies with normal volunteers have accordingly been developed with the NMDA models to study the mechanism of schizophrenia ${ }^{49}$ Since schizophrenia is a chronic mental disorder that develops gradually over time, 
the negative symptoms and cognitive dysfunction develop early and then positive symptoms gradually emerged. ${ }^{22}$ Therefore, an appropriate model design, such as suitable dose range or treatment duration, would be important to conform to the symptoms observed in established schizophrenia. For instance, acute ketamine treatment models, either with animals or human subjects, would at best observe the early symptoms of schizophrenia. ${ }^{22,54}$ Furthermore, administration of subanesthetic doses of ketamine to neuroleptic-free schizophrenic patients resulted in brief exacerbation of both positive and negative symptoms with further decrements in recall and recognition memory. The patients also displayed greater ketamine-induced impairments in free recall than normal subjects. Auditory hallucinations and paranoia were also observed in patients but not in normal subjects. These results demonstrate that ketamine is associated with exacerbation of core psychotic and cognitive symptoms in schizophrenia. ${ }^{55}$ It has been shown that NE-100, a putative sigma ${ }_{1}$ receptor antagonist, inhibited ketamine-elicited discriminative stimulus effects in a rat model, suggesting the involvement of sigma receptors in the pathogenesis of some psychiatric disorders. ${ }^{56}$ Although these mechanisms are yet to be elucidated, it is reasonable to assume that PCP-ketamine/ NMDA receptors interact with other receptors or systems to exacerbate or alleviate the effects.

Taken together, PCP or ketamine may be a useful tool to study the mechanism of schizophrenia, but the results should be interpreted with more detailed information.

\section{Ketamine psychedelic therapy (KPT)}

In Russia, it has been claimed that ketamine $(2.5 \mathrm{mg} / \mathrm{kg}$, intramuscular) was effective for treatment of alcoholism. ${ }^{57}$ The aversive therapy, based on the frightening experience of ketamine-elicited psychedelic emergence phenomenon, was used before cognitive therapy sessions to induce negative reinforcement. Total abstinence for more than 1 year was observed in $65.8 \%$ of alcoholic patients in the KPT group, compared to $24 \%$ of the conventional treatment group. ${ }^{57}$ Similar effectiveness of KPT for heroin addiction treatment was reported and repeated sessions of KPT were more effective than those of single KPT. ${ }^{58}$

\section{Toxicology and adverse effects Psychedelic effects and dependence}

Ketamine, like PCP, can lead to vivid dreams (both pleasant and frightening) and hallucinations. ${ }^{59}$ Although ketamine has a good safety profile, patients in recovery following ketamine anesthesia may experience the "emergence phenomenon", which commonly include feelings of mind-body dissociation (out-of the body or near death experiences) with difficulty in movement, sensations of floating, severe disorientation, vivid dreams, and delirium. ${ }^{11,14}$ It has been shown that the $\mathrm{R}(-)$ isomer produces a higher rate of emergence reactions and more agitated behavior than the $\mathrm{S}(+)$ isomer. ${ }^{11}$ Furthermore, the antagonistic effects of ketamine on the NMDA receptors include hyperexcitability, severe agitation, and paranoid psychosis. ${ }^{12,13}$ Ketamine also has dopaminergic actions, which may be related to its abuse. ${ }^{12,13,60}$ Although ketamine was originally believed to have a low potential for dependence, $78.9 \%$ of Hong Kong ketamine abusers, defined by the governmental Central Registry of Drug Abuse (CRDA) as those who come into contact with treatment, health care, social service, welfare, and law enforcement organizations, developed into dependence after regular use for 1 year. ${ }^{61}$ In addition, on stopping ketamine use, $53.5 \%$ of these abusers reported withdrawal symptoms including fatigue, excessive yawning, aggressive or hostile behavior, feeling angry, irritable, or depressed. In Singapore, two ketamine-dependent patients were observed to manifest psychotic effects that include multimodal hallucinatory experiences, a sense of slowing, paranoid ideation, and enhancement of sexual, musical, and sensory enjoyment. ${ }^{62}$ The effect of ketamine on driving remains to be observed but a negative effect on driving performance has been suggested. ${ }^{63}$

\section{Cognitive impairment}

In addition to producing alcohol-like effects on mood, the acute effects of ketamine, studied in human volunteers, include cognitive impairments, including severe impairments of working, episodic, and semantic memory, as well as psychotogenic and dissociative effects. ${ }^{26}$ Persistent effects, including semantic memory impairment and dissociative and schizotypal symptomatology, have been observed in recreational users 3 days after ketamine administration, but not in healthy volunteers administered a single ketamine dose. ${ }^{64} \mathrm{~A}$ 3-year follow-up on recreational ketamine users by the same research group found that semantic memory impairments associated with recreational ketamine were reversible upon reduction of use; however, impairments to episodic memory and attentional functioning may be longlasting. In more recent studies, frequent ketamine users were found to have impaired working memory, verbal recognition memory, and planning compared to infrequent ketamine users, abstinent ketamine users, and individuals with no history of ketamine use.$^{65}$ Compared to two groups of controls with no history of ketamine use (polydrug users or no drug 
use), however, frequent ketamine users, infrequent ketamine users, and abstinent ketamine users all had higher levels of dissociative symptoms, schizophrenia-like symptoms, or delusions. ${ }^{65}$ Follow-up assessments conducted 12 months after the initial assessments found persistent decrements in spatial working and pattern recognition memory, and increased dissociative symptoms, delusional ideation, and depressive symptoms in persistent frequent users. ${ }^{66}$ Schizotypal symptoms and perceptual distortions may persist after cessation of ketamine use. ${ }^{67}$

\section{Brain structural abnormality}

To learn the long-term effects of ketamine use on brain structures, a recent study performed on ketamine-dependent users with magnetic resonance imaging technique has revealed a dose-dependent association between chronic ketamine use and reduction of gray matter volume in bilateral frontal cortex as well as the frontal white matter fractional anisotropy. These pathological changes in brain have also been observed in patients with chronic schizophrenia. ${ }^{68,69}$

\section{Damage to the urinary tract}

Urological side effects associated with ketamine use have been reported among the street ketamine users and chronic pain patients. ${ }^{70-73}$ Although the dosage and duration of ketamine use causing severe side-effects are still unclear, lower urinary tract symptoms, which include dysuria, an increase of urination frequency, nocturia, urgency, suprapubic discomfort during micturition, and gross hematuria, were observed in these ketamine users or patients. ${ }^{70-72}$ Biopsy specimens of the ketamine users with those urinary tract symptoms showed various degrees of epithelial inflammation similar to that seen in chronic interstitial cystitis. ${ }^{73}$

In some patients abusing or treated with ketamine, long-term irreversible damage can lead to renal failure and dialysis, which may cause a significant burden to healthcare resources. ${ }^{71,73}$

\section{Genotoxic effects}

Ketamine hydrochloride, a secondary amine, is used as an injectable anesthetic and analgesic and thus avoids the production of nitroso compounds in the stomach. ${ }^{74}$ However, recreational ketamine is usually ingested by oral route in its powder or tablet form, implying the possibility of forming ketamine's nitroso derivative, $N$-nitrosoketamine (NKT). Both ketamine and NKT have been shown to possess genotoxicity using micronucleus assay in Chinese hamster ovary cells. ${ }^{74}$ Therefore, ketamine, like many other abused drugs such as LSD, cocaine, and opium, should be considered genotoxic. ${ }^{75}$

\section{Sexual assaults and date rape drug}

Ketamine, along with other drugs such as flunitrazepam and GHB that could facilitate sexual assault, is illicitly used as a socalled "date-rape drug" ${ }^{76,77}$ In China, a high proportion (45.8\%) of sex impulse or violence due to ketamine use was reported. ${ }^{4}$ The dissociative state with amnesia and analgesia after ketamine administration suggests that ketamine should be included in any forensic examination of sexual assault cases. ${ }^{78}$

\section{Problematic use of ketamine: epidemiology and control}

Ketamine has not yet been scheduled in the Conventions of the United Nations. Therefore, the prevalence of ketamine abuse, if any, is rather underestimated. However, the surge of illicit ketamine use has pushed many countries to take legal actions. For example, ketamine has been placed in Schedule III in the United States since 1999 and Class C in the United Kingdom since 2006. Although illicit ketamine use has become a worldwide phenomenon, the severity degree of the problem varies from region to region. For instance, in Hong Kong ketamine has replaced heroin as the most prominent drug of abuse since 2000.6 In the United States, emergency room visits due to ketamine use have surged 2,000\% between 1995 and 2002. ${ }^{79}$ Below are brief summaries regarding what is known about the ketamine abuse situation with emphasis on some countries in Southeast and East Asia.

\section{China}

In a survey conducted on 720 ketamine abusers, it was found that most of them used the drug in recreational settings; $12.7 \%$ suffered from acute toxicity; $13.5 \%$ had attack activities; $40.3 \%$ had sex impulse; $5.5 \%$ had violent sex; and $12.1 \%$ suffered from mental disorders. ${ }^{4}$ Because those who use illicit ketamine tend to be polydrug users, the association of ketamine with aberrant sexual behaviors needs further investigation. It was reported that men who have sex with men (MSM) with continued human immunodeficiency virus (HIV) transmission-risk behavior were more likely to use ketamine.$^{80}$ At the advent of an escalating HIV situation, it would be important to study if there is a connection between ketamine use and HIV transmission among MSM or other club drug users. 


\section{Hong Kong}

Since the late 1990s, drug policy in Hong Kong has entered a "New Drug Era". Heroin, which had dominated the illicit drug scenes for more than half a century, was joined and, among young users, supplanted by psychoactive drugs such as MDMA and ketamine according to the database of CRDA, which compiles the data of drug abusers who come into contact with law enforcement, treatment, health care, and social service organizations. ${ }^{6}$ While MDMA remained popular throughout the $1990 \mathrm{~s}$, ketamine is now the drug of choice among young drug abusers, as the percentage of ketamine abusers rose from $60 \%$ to $70 \%$ in the early 2000 s to over $80 \%$ in the late $2000 \mathrm{~s}$. By contrast, only about $2 \%$ of young drug abusers in CRDA are reported heroin users at present. ${ }^{6}$ The rapid increase of young peoples' drug use may be explained by a global trend of "normalization of recreational drug use". ${ }^{6,81}$ Some adverse reactions such as urinary tract dysfunctions have been identified. ${ }^{73}$

Because of its severe abuse, ketamine has been classified as a Schedule I drug in Hong Kong since 2000.

\section{Indonesia}

According to the survey conducted by National Narcotic Board and University of Indonesia, the prevalence of drug use among students of junior and senior high schools (grade 7-12) in all 33 provinces nationwide in 2009 was $4.7 \%$ (estimated number 921,695) while the prevalence among workers/laborers was $5.2 \%$ (estimated number 5,437,120). Among students who used drugs in 2009 , ketamine contributed $1.8 \%$, while within the group of workers/laborers, $1.1 \%$ using ketamine. ${ }^{82}$

\section{Malaysia}

Recreational ketamine use has been observed in Malaysia, and there are also reports that ketamine is gaining popularity outside of night clubs or night life scenes. Illicit ketamine induced frequency of micturition in a young Malay woman has been reported. ${ }^{7}$ Although there are no data regarding the prevalence of ketamine abuse in Malaysia, seizures of ketamine have been showing a rising trend. In 2007, $177.91 \mathrm{~kg}$ was seized, $240.62 \mathrm{~kg}$ in 2008 , and $378 \mathrm{~kg}$ in $2009 .{ }^{83}$

\section{Taiwan}

In 2005, a National Household Survey on Health and Substance Abuse was conducted on the population aged between 12-64 years old in Taiwan. ${ }^{84}$ The prevalence for people ever used illicit drugs was $1.2 \%$. Among them, ketamine abusers ranked third (22.0\%), behind amphetamines (49\%) and MDMA (35.1\%). In recent surveys of school-attending adolescents, ketamine is overtaking MDMA as the leading drug of abuse in this population. ${ }^{85}$ Another study performed with urine tests on 931 specimens collected from illicit drug use arrestees in 2002, a drug positive rate of $74 \%$ and 39 drugs were identified. The positive rate of ketamine use was $4.7 \%$ (44/931). Club drug (including ketamine) users tended to be younger (mostly under 27 years old), urbanized, better educated, and with a smaller gender gap (male/female ratio $<3.5) .{ }^{8}$ Ketamine is usually abused with other drugs. For example, "Trinity" is a description for a sequence of polydrug use at a club with MDMA first, followed by ketamine, and then marijuana. ${ }^{9}$ Ketamine associated bladder dysfunction has been reported in Taiwan. ${ }^{71}$ The trend of ketamine seizures has been rising: from $598.7 \mathrm{~kg}$ in $2007,799.5 \mathrm{~kg}$ in $2008,1186.4 \mathrm{~kg}$ in 2009 , to $2408.9 \mathrm{~kg}$ in 2010 (January through October) ${ }^{86}$

Ketamine has been placed in Schedule III in Taiwan since 2002. Recently, a rescheduling of ketamine to Schedule I or II has been urged by the Legislative Yuan (Congress).

These preliminary data on ketamine use or seizures clearly indicate that the trend of ketamine abuse is on the rise in some countries of Southeast and East Asia. Further action to tackle this emerging problem is desperately needed.

\section{Prevalence of illicit ketamine injection}

Ketamine evolved from a human anesthetic into a recreational drug with a primary goal to experience a "k-hole" in dance clubs in the early 1980s. ${ }^{17}$ Ketamine injection has become an increasingly common practice among young injection drug users (IDUs) because the "k-hole" state is more reliably achieved and intensely experienced by injecting the drug. ${ }^{17}$ However, due to the dearth of epidemiological data, little is known about ketamine injection associated risk behaviors, or the demographic characteristics of ketamine injectors. The escalating HIV situation by needle-sharing among IDUs would make such an investigation indispensable for effective prevention and control.

\section{Conclusion}

Ketamine is an anesthetic and analgesic with a wide safety margin. However, the benefit of safety in therapeutic use was offset by its emergence phenomenon and hallucinogenic effects. The recreational use of ketamine to experience a "k-hole" and other hallucinatory effects, enhancement of sexual impulse has further confined its usage and the drug was accordingly controlled tightly in many countries. Recent observations that 
ketamine may be associated with irreversible urinary tract dysfunction also tarnished its safety profile. However, a recent finding that ketamine could be useful in treating major depression, one of the most serious diseases in the 21 st century, has given this old drug a new momentum.

So far, ketamine has not been scheduled in the conventions of the United Nations. Nutt et al adopted assessment parameters including physical harm, dependence, and social harm to score the overall harm since drugs and ketamine appear to cause more harm than some of the United Nations scheduled drugs such as LSD, MDMA, methylphenidate, and GHB. ${ }^{87}$ Ketamine use has also resulted in several medical complications that have not been documented previously. ${ }^{88}$ These results also imply that the danger of ketamine may have been underestimated.

While the diversified classification of drug scheduling among different countries may be due to various levels of ketamine abuse, it may also result from underestimating the extent or severity of problems associated with ketamine abuse or an irrational scale to assess the harm of ketamine (and other drugs). ${ }^{87-89}$ Therefore, the severity levels of the ketamineassociated problem should be scrutinized more carefully and objectively. To prevent ketamine from spreading and evolving into an epidemic, a thorough survey on the prevalence and characteristics of illicit ketamine use is imperative so that suitable policy and measures can be taken.

On the other hand, if ketamine is indeed a remedy for treating depression, it would be a priority to learn its adverse effects such as dependence potential, cognitive impairment, and irreversible urinary tract dysfunction for long-term use. For central nervous system drugs with known or suspected dependence/abuse potential, better harmonization of risk management and post-marketing surveillance is important from both drug development and regulatory perspectives..$^{90}$ Apparently, more clinical research on the risks and benefits of ketamine use is indispensable. Perhaps Paraselsus' old saying that "all substances are poisons; the right dose [or perhaps the right dose for the right use in the right circumstances] differentiates a remedy from a poison" still holds true.

\section{Acknowledgments}

The study was supported in part by grants from Kaohsiung Medical University (KMU-Q100012) and from Taiwan Food and Drug Administration, Department of Health, Taiwan, R.O.C. (DOH100-FDA-61402).

\section{Disclosure}

The authors report no conflicts of interest in this work.

\section{References}

1. McKetin R, Kozel N, Douglas J, et al. The rise of methamphetamine in Southeast and East Asia. Drug Alcohol Rev. 2008;27(3):220-228.

2. Navaratnam V, Wong PL, editors. Report of the Asian Multicity Epidemiology Workgroup 2002. International Monograph Series No. 16. Penang, Malaysia: Centre for Drug Research, Universiti Sains Malaysia; 2003.

3. Degenhardt L, Copeland J, Dillon P. Recent trends in the use of "club drugs": an Australian review. Subst Use Misuse. 2005;40(9-10): $1241-1256$

4. Lian Z, Liu Z, Liu R, et al. Epidemiological survey of ketamine in China. Chin J Drug Depend. 2005;14(4):280-283.

5. Li JH, Liu SF, Yu WJ. Patterns and trends of drug abuse in Taiwan: a brief history and report from 2000 through 2004. Epidemiologic trends in drug abuse, Vol II, Proceedings of the Community Epidemiology Work Group; 2005 June; Denver, CO. Bethesda, MD: NIDA, NIH, DHHS; 2006.

6. Cheung YW, Cheung, NWT. Drug policy in Hong Kong: changes and challenges. Anti-Drug International Conference; 2010 June 2-3; Taipei, Taiwan.

7. Noorzurani R, Vicknasingam B, Narayanan S. Illicit ketamine induced frequency of micturition in a young Malay woman. Drug Alcohol Rev. 2010;29(3):334-336

8. Liu C, Li JH, Tsay WI, Hsu J. Drug use and profile of individuals arrested on drug-related charges in Taiwan. J Food Drug Anal. 2005; 13(2):3-8.

9. Leung KS, Li JH, Tsay WI, et al. Dinosaur girls, candy girls, and Trinity: voices of Taiwanese club drug users. J Ethn Subst Abuse. 2008;7(3):237-257.

10. Domino EF, Chodoff P, Corssen G. Pharmacologic effects of CI-581, a new dissociative anesthetic in man. Clin Pharmacol Ther. 1965; 6:279-291.

11. Bergman AS. Ketamine: review of its pharmacology and its use in pediatric anesthesia. Anesth Prog. 1999;46(1):10-20.

12. Hansen G, Jensen SB, Chandresh L, Hilden T. The psychotropic effect of ketamine. J Psychoactive Drugs. 1988;20(4):419-425.

13. Pal HR, Berry N, Kumar R, Ray R. Ketamine dependence. Anaesth Intensive Care. 2002;30(3):382-384

14. Wolff K, Winstock AR. Ketamine from medicine to misuse. CNS Drugs. 2006;20(3):199-218.

15. Harrison NL, Simmonds MA. Quantitative studies on some antagonists of N-methyl D-aspartate in slices of rat cerebral cortex. Br J Pharmacol. 1985;84(2):381-391.

16. Walker AK. Intramuscular ketamine in a developing country. Experience in the British Solomon Islands. Anaesthesia. 1972;27(4):408-414.

17. Lankenau SE, Clatts MC. Drug injection practices among high-risk youths: The first shot of ketamine. J Urban Health. 2004;81(2): 232-248.

18. Reier C. Ketamine -"dissociative agent" or hallucinogen? N Engl J Med. 1971;284(14):791-792.

19. Siegel RK. Phencyclidine and ketamine intoxication: a study of four populations of recreational users. NIDA Res Monogr. 1978;21: 119-147.

20. Brau ME, Sander F, Vogel W, Hempelmann G. Blocking mechanisms of ketamine and its enantiomers in enzymatically demyelinated peripheral nerve as revealed by single-channel experiments. Anesthesiology. 1997;86(2):394-404.

21. Duque JC, Oleskovicz N, Guirro EC, Valadao CA, Soares VE. Relative potency of ketamine and $\mathrm{S}(+)-$ ketamine in dogs. $J$ Vet Pharmacol Ther. 2008;31(4):344-348.

22. Krystal H, Karper LP, Seibyl JP, et al. Subanesthetic effects of the noncompetitive NMDA antagonist, ketamine, in humans. Psychotomimetic, perceptual, cognitive, and neuroendocrine responses. Arch Gen Psychiatry.1994;51(3):199-214.

23. Newcomer JW, Farber NB, Jevtovic-Todorovic V, et al. Ketamineinduced NMDA receptor hypofunction as a model of memory impairment and psychosis. Neuropsychopharmacology. 1999;20(2):106-118. 
24. Hirota K, Okawa H, Appadu BL, Grandy DK, Devi LA, Lambert DG. Sterioselective interaction of ketamine with recombinant mu, kappa and delta opioid receptors expressed in Chinese hamster ovary cells. Anesthesiology. 1999;90(1):174-182.

25. Nishimura N, Sato K, Okada T, et al. Ketamine inhibits monoamine transporters expressed in human embryonic kidney 293 cells. Anesthesiology. 1998;88(3):768-774.

26. Curran HV, Morgan C. Cognitive, dissociative and psychotogenic effects of ketamine in recreational users on the night of drug use and 3 days later. Addiction. 2000;95(4):575-590.

27. Weiner AL, Vieira L, McKay CA, Bayer MJ. Ketamine abusers presenting to the emergency department: a case series. J Emerg Med. 2000;18(4):447-451.

28. Koob GF. Anatomy, pharmacology and function of reward pathways. Trends Pharmacol Sci. 1992;13(5):177-185.

29. White PF, Way WL, Trevor AJ. Ketamine: its pharmacology and therapeutic uses. Anaesthesiology. 1982;56(2):119-136.

30. Walker SM, Goudas LC, Cousins MJ, Carr DB. Combination spinal analgesic chemotherapy: a systematic review. Anesth Analg. 2002;95(3): 674-715.

31. Hocking G, Cousins MJ. Ketamine in chronic pain management: an evidence-based review. Anesth Analg. 2003;97(6):1730-1739.

32. Zeilhofer HU, Swandulla D, Geisslinger G, Brune K. Differential effects of ketamine enantiomers on NMDA receptor currents in cultured neurons. Eur J Pharmacol. 1992;213(1):155-158.

33. Reich DL, Silvay G. Ketamine: an update on the first twenty-five years of clinical experience. Can J Anaesth. 1989;36(2):186-197.

34. Vollenweider FX, Leenders KL, Oye I, Hell D, Angst J. Differential psychopathology and patterns of cerebral glucose utilization produced by (S)- and (R) -ketamine in healthy volunteers using positron emission tomography (PET). Eur Neuropsychopharmacol. 1997;7(1):25-38.

35. Pabelick CM, Rehder K, Jones KA, Shumway R, Lindahl SG, Warner DO. Stereospecific effects of ketamine enantiomers on canine tracheal smooth muscle. Br J Pharmacol. 1997;121(7):1378-1382.

36. Lankveld DP, Driessen B, Soma LR, et al. Pharmacodynamic effects and pharmacokinetic profile of a long-term continuous rate infusion of racemic ketamine in healthy conscious horses. $J$ Vet Pharmacol Ther. 2006;29(6):477-488.

37. Cheng PS, Fu CY, Lee CH, Liu C, Chien CS. GC-MS quantification of ketamine, norketamine, and dehydronorketamine in urine specimens and comparative study using ELISA as the preliminary test methodology. J Chromatogr B Analyt Technol Biomed Life Sci. 2007;852(1-2):443-449

38. Yanagihara Y, Kariya S, Ohtani M, et al. Involvement of CYP2B6 in n-demethylation of ketamine in human liver microsomes. Drug Metab Dispos. 2001;29(6):887-890.

39. Hijazi Y, Boulieu R. Contribution of CYP3A4, CYP2B6, and CYP2C9 isoforms to $\mathrm{N}$-demethylation of ketamine in human liver microsomes Drug Metab Dispos. 2002;30(7):853-858.

40. Lo JN, Cumming JF. Interaction between sedative premedicants and ketamine in man in isolated perfused rat livers. Anesthesiology. 1975;43(3):307-312

41. White PF, Vasconez LO, Mathes SA, Way WL, Wender LA. Comparison of midazolam and diazepam for sedation during plastic surgery. Plast Reconstr Surg. 1988;81(5):703-712.

42. Skolnick P, Popik P, Trullas R. Glutamate-based antidepressants: 20 years on. Trends Pharmacol Sci. 2009;30(11):563-569.

43. Diazgranados N, Ibrahim L, Brutsche NE, et al. A randomized add-on trial of an N-methyl-D-aspartate antagonist in treatment-resistant bipolar depression. Arch Gen Psychiatry. 2010;67(8):793-802.

44. Zhao Y, Sun L. Antidepressants modulate the in vitro inhibitory effects of propofol and ketamine on norepinephrine and serotonin transporter function. J Clin Neurosci. 2008;15(11):1264-1269.

45. Li N, Lee B, Liu RJ, et al. mTOR-dependent synapse formation underlies the rapid antidepressant effects of NMDA antagonists. Science. 2010;329(5994):959-964.
46. Vollenweider FX, Kometer M. The neurobiology of psychedelic drugs: implications for the treatment of mood disorders. Nat Rev Neurosci. 2010;11(9):642-651.

47. Hashimoto K. Emerging role of glutamate in the pathophysiology of major depressive disorder. Brain Res Review. 2009;61(2):105-123.

48. Belmaker RH, Agam G. Major depressive disorder. $N$ Engl J Med. 2008;358(1):55-68.

49. Javitt DC. Glutamate as a therapeutic target in psychiatric disorders. Mol Psychiatry. 2004;9(11):984-997.

50. Goff DC, Hill M, Barch D. The treatment of cognitive impairment in schizophrenia. Pharmacol Biochem Behav. 2010; Nov 27. [Epub ahead of print]. doi:10.1016/j.pbb.2010.11.009.

51. Davis K, Kahn R, Ko G, Davidson M. Dopamine in schizophrenia: a review and reconceptualization. Am J Psychiatry. 1991;148(11): 1907-1917.

52. Curran C, Byrappa N, McBride A. Stimulant psychosis: systematic review. Br J Psychiatry. 2004;185:196-204.

53. Javitt DC, Zukin SR. Recent advances in the phencyclidine model of schizophrenia. Am J Psychiatry. 1991;148(10):1301-1308.

54. Duncan EJ, Madonick SH, Parwani A, et al. Clinical and sensorimotor gating effects of ketamine in normals. Neuropsychopharmacology. 2001;25(1):72-83.

55. Malhotra AK, Pinals DA, Adler CM, et al. Ketamine-induced exacerbation of psychotic symptoms and cognitive impairment in neuroleptic-free schizophrenics. Neuropsychopharmacology. 1997;17(3):141-150.

56. Narita M, Yoshizawa K, Aoki K, Takagi M, Miyatake M, Suzuki T. A putative sigma 1 receptor antagonist NE-100 attenuates the discriminative stimulus effects of ketamine in rats. Addict Biol. 2001;6(4):373-376.

57. Krupitsky EM, Grinenko AY. Ketamine psychedelic therapy (KPT): a review of the results of ten years of research. J Psychoactive Drugs. 1997;29(2):165-183.

58. Krupitsky EM, Burakov AM, Dunaevsky IV, Romanova TN, Slavina TY, Grinenko AY. Single versus repeated sessions of ketamine-assisted psychotherapy for people with heroin dependence. J Psychoactive Drugs. 2007;39(1):13-19.

59. Green SM, Li J. Ketamine in adults: what emergency physicians need to know about patient selection and emergence reactions. Acad Emerg Med. 2000;7(3):278-281.

60. Moghaddam B, Adams B, Verma A, Daly D. Activation of glutamatergic neurotransmission by ketamine: a novel step in the pathway from NMDA receptor blockade to dopaminergic and cognitive disruptions associated with the prefrontal cortex. J Neurosci. 1997;17(8):2921-2927.

61. Chen R, Lee AM, Chan R. A study on the cognitive impairment and other harmful effects from ectasy and ketamine abuse. In: Hong Kong Chinese 2004. Hong Kong: Narcotics Division, Security Bureau, Government of the Hong Kong Special Administrative Region; 2004.

62. Lim DK. Ketamine associated psychedelic effects and dependence. Singapore Med J. 2003;44(1):31-34.

63. Penning R, Veldstra JL, Daamen AP, Olivier B, Verster JC. Drugs of abuse, driving and traffic safety. Curr Drug Abuse Rev. 2010; 3(1):23-32.

64. Morgan CJ, Mofeez A, Brandner B, Bromley L, Curran HV. Ketamine impairs response inhibition and is positively reinforcing in healthy volunteers: a dose-response study. Psychopharmacology. 2004;172(3):298-308

65. Morgan CJ, Muetzelfeldt L, Curran HV. Ketamine use, cognition and psychological wellbeing: a comparison of frequent, infrequent and ex-users with polydrug and non-using controls. Addiction. 2009;104(1):77-87.

66. Morgan CJ, Muetzelfeldt L, Curran HV. Consequences of chronic ketamine self-administration upon neurocognitive function and psychological wellbeing: a 1-year longitudinal study. Addiction. 2010;105:121-133.

67. Morgan CJ, Monaghan L, Curran HV. Beyond the K-hole: a 3-year longitudinal investigation of the cognitive and subjective effects of ketamine in recreational users who have substantially reduced their use of the drug. Addiction. 2004;99(11):1450-1461. 
68. Liao Y, Tang J, Corlett PR, et al. Reduced dorsal prefrontal gray matter after chronic ketamine use. Biol Psychiatry. 2011;69(1):42-48.

69. Liao Y, Tang J, Ma M, et al. Frontal white matter abnormalities following chronic ketamine use: a diffusion tensor imaging study. Brain. 2010;133(Pt 7):2115-2122.

70. Storr TM, Quibell R. Can ketamine prescribed for pain cause damage to the urinary tract? Palliat Med. 2009;23(7):670-672.

71. Tsai TH, Cha TL, Lin CM, et al. Ketamine-associated bladder dysfunction. Int J Urol. 2009;16(10):826-829.

72. Mason K, Cottrell AM, Corrigan AG, Gillatt DA, Mitchelmore AE. Ketamine-associated lower urinary tract destruction: a new radiological challenge. Clin Radiol. 2010;65(10):795-800.

73. Chu PS, Ma WK, Wong SC, et al. The destruction of the lower urinary tract by ketamine abuse: a new syndrome? BJU Int. 2008;102(11): 1616-1622.

74. Toyama Y, Shimizu H, Suzuki Y, Miyakoshi Y, Yoshioka H. Genotoxic effects of N-nitrosoketamine and ketamine as assessed by in vitro micronucleus test in Chinese hamster lung fibroblast cell line. Environ Health Prev Med. 2006;11(3):120-127.

75. Li JH, Lin LF. Genetic toxicology of abused drugs: a brief review. Mutagenes. 1998;13(6):557-565.

76. Woodworth T. DEA congressional testimony before the House Commerce Committee subcommittee on oversight and investigations. March 11, 1999. Available from: http://www.justice.gov/dea/pubs/ cngrtest/ct990311.htm. Accessed February 9, 2011.

77. Negrusz A, Gaensslen RE. Analytical developments in toxicological investigation of drug-facilitated sexual assault. Anal Bioanal Chem. 2003;376(8):1192-1197.

78. Anglin D, Spears KL, Hutson HR. Flunitrazepam and its involvement in date or acquaintance rape. J Accid Emerg Med. 1997;4(4):323-326.

79. DAWN. Emergency department trends from the Drug Abuse Warning Network DAWN: final estimates 1995-2002. DHHS Publication no. (SMA) 03-3780. Rockville, MD: Department of Health and Human Services; 2003.

80. Fox J, White PJ, Macdonald N, et al. Reductions in HIV transmission risk behavior following diagnosis of primary HIV infection: a cohort of high-risk men who have sex with men. HIV Med. 2009;10(7): $432-438$.
81. Parker H, Aldridge J, Measham F. Illegal Leisure: The normalization of adolescent recreational drug use. London, UK: Routledge; 1998.

82. National Narcotic Board (BNN). Survey on Drug Use among Workers and Students. Jakarta, Indonesia: National Narcotic Board; 2009.

83. Royal Malaysian Police. Narcotics Investigation Department Statistical Book. Kuala Lumpur, Malaysia: Royal Malaysian Police; 2010.

84. Li JH, Liang KY, Wu Si, et al. Joint Report of National Household Survey on Health and Substance Abuse 2005. National Bureau of Controlled Drugs, National Bureau of Health Promotion, National Health Research Institutes. Report of National Household Survey on Health and Substance Abuse 2005. Taipei, Taiwan: Department of Health; 2006.

85. Chen WJ, Fu TC, Ting TT, et al. Use of ecstasy and other psychoactive substances among school-attending adolescents in Taiwan: national surveys 2004-2006. BMC Public Health. 2009;9:27.

86. Food and Drug Administration, Department of Health, Executive Yuan. Statistics of drug abuse in Taiwan [Updated 2011 Feb 20]. Available from: http://www.fda.gov.tw/files/site_content. Accessed February 24, 2011.

87. Nutt D, King LA, Saulsbury W, Blakemore C. Development of a rational scale to assess the harm of drugs of potential misuse. Lancet. 2007; 369(9566):1047-1053.

88. Ricaurte GA, McCann. Recognition and management of complications of new recreational drug use. Lancet. 2005;365(9477): 2137-2145.

89. Van Amsterdam JG, Best W, Opperhuizen A, de Wolff FA. Evaluation of a procedure to assess the adverse effects of illicit drugs. Regul Toxicol Pharmacol. 2004;39(1):1-4.

90. Henningfield JE, Schuster CR. Risk management and post-marketing surveillance of CNS drugs. Drug and Alcohol Depend. 2009; 105(Suppl 1):S56-S64.

91. Portmann S, Kwan HY, Theurillat R, Schnitz A, Mevissen M, Thormann W. Enantioselective capillary electrophoresis for identification and characterization of human cytochrome P450 enzymes which metabolize ketamine and norketamine in vitro. J Chromatogr A. 2010;1217(51):7942-7948.

92. HijaziY, Boulieu R. Contribution of CYP3 A4, CYP2B6, and CYP2C9 isoforms to N-demethylation of ketamine in human liver microsomes. Drug Metab Dispos. 2002;30(7):853-858.
Substance Abuse and Rehabilitation

\section{Publish your work in this journal}

Substance Abuse and Rehabilitation is an international, peer-reviewed, open access journal publishing original research, case reports, editorials, reviews and commentaries on all areas of addiction and substance abuse and options for treatment and rehabilitation. The manuscript management system is completely online and includes a very quick and

\section{Dovepress}

fair peer-review system. Visit http://www.dovepress.com/testimonials php to read real quotes from published authors. 